\title{
Musical hallucinations: review of treatment effects
}

\author{
Jan A. F. Coebergh ${ }^{1,2,3 *}$, R. F. Lauw ${ }^{4}$, R. Bots ${ }^{5}$, I. E. C. Sommer ${ }^{6,7}$ and J. D. Blom ${ }^{4,8}$ \\ ' Department of Neurology, Haga Hospital, The Hague, Netherlands, ${ }^{2}$ Department of Neurology, Ashford/St. Peter's Hospital, \\ Chertsey, UK, ${ }^{3}$ Department of Neurology, St. George's Hospital, London, UK, ${ }^{4}$ Parnassia Psychiatric Institute, The Hague, \\ Netherlands, ${ }^{5}$ 'S Heeren Loo, Noordwijk, Netherlands, ${ }^{6}$ Department of Psychiatry, University Medical Center Utrecht, \\ Utrecht, Netherlands, ${ }^{7}$ Brain Centre Rudolf Magnus, Utrecht, Netherlands, ${ }^{8}$ Department of Psychiatry, University of \\ Groningen, Groningen, Netherlands
}

Background: Despite an increased scientific interest in musical hallucinations over the past 25 years, treatment protocols are still lacking. This may well be due to the fact that musical hallucinations have multiple causes, and that published cases are relatively rare. Objective: To review the effects of published treatment methods for musical hallucinations.

Methods: A literature search yielded 175 articles discussing a total number of 516

\section{OPEN ACCESS}

Edited by:

Frank Larøi,

University of Liege, Belgium

Reviewed by:

Tuomas Eerola

University of Durham, UK

Daniel Collerton,

Northumberland, Tyne and Wear NHS

Foundation Trust, UK

*Correspondence:

Jan A. F. Coebergh Department of Neurology, Ashford/St. Peter's Hospital, Guildford Road KT17

OPZ Chertsey, UK

jan.coebergh@asph.nhs.uk

Specialty section:

This article was submitted to

Psychopathology,

a section of the journal

Frontiers in Psychology

Received: 01 April 2015

Accepted: 28 May 2015

Published: 16 June 2015

Citation:

Coebergh JAF, Lauw RF, Bots $R$,

Sommer IEC and Blom JD (2015)

Musical hallucinations: review of treatment effects.

Front. Psychol. 6:814.

doi: 10.3389/fpsyg.2015.00814 cases, of which 147 articles discussed treatment in 276 individuals. We analyzed the treatment results in relation to the etiological factor considered responsible for the mediation of the musical hallucinations, i.e., idiopathic/hypoacusis, psychiatric disorder, brain lesion, and other pathology, epilepsy or intoxication/pharmacology.

Results: Musical hallucinations can disappear without intervention. When hallucinations are bearable, patients can be reassured without any other treatment. However, in other patients musical hallucinations are so disturbing that treatment is indicated. Distinct etiological groups appear to respond differently to treatment. In the hypoacusis group, treating the hearing impairment can yield significant improvement and coping strategies (e.g., more acoustic stimulation) are frequently helpful. Pharmacological treatment methods can also be successful, with antidepressants being possibly more helpful than antiepileptics (which are still better than antipsychotics). The limited use of acetylcholinesterase inhibitors has looked promising. Musical hallucinations occurring as part of a psychiatric disorder tend to respond well to psychopharmacological treatments targeting the underlying disorder. Musical hallucinations experienced in the context of brain injuries and epilepsy tend to respond well to antiepileptics, but their natural course is often benign, irrespective of any pharmacological treatment. When intoxication/pharmacology is the main etiological factor, it is important to stop or switch the causative substance or medication.

Conclusion: Treatments for musical hallucinations tend to yield favorable results when they target the main etiological factor of these phenomena. There is a need to establish the natural course of musical hallucinations, their response to non-pharmacological treatments, and their effects on the patient's quality of life. There is also a need to standardize the assessment of treatment responses, and document long-term follow up.

Keywords: Auditory Charles Bonnet syndrome, auditory hallucination, brain lesion, epilepsy, intoxication/pharmacology, psychiatric disorder 


\section{Introduction}

Musical hallucinations ( $\mathrm{MH})$ are auditory hallucinations characterized by songs, tunes, melodies, harmonics, rhythms, and/or timbres (Coebergh et al., 2009). The scientific interest in these phenomena has increased significantly over the past 25 years, but so far no evidence-based treatments have been established. The principle reason for this would seem to be that published case series are relatively small, and that the mechanisms responsible for the mediation of $\mathrm{MH}$ are probably diverse. Furthermore, case reports tend to over represent positive responses, as negative responses to specific medication are rarely published. We therefore endeavored to identify which treatments have been tried under which circumstances, and what their effect has been upon the $\mathrm{MH}$.

$\mathrm{MH}$ are commonly divided into two groups. When they occur without the presence of any associated pathological abnormalities-with the exception of hearing impairment (hypoacusis)-they are called idiopathic $\mathrm{MH}$. When there are associated pathological abnormalities, they are named symptomatic MH (Coebergh et al., 2009). The most relevant etiological factors for $\mathrm{MH}$, as reported in the literature, are brain injuries, epilepsy, psychiatric disorder, and intoxication/pharmacology (Berrios, 1990; Keshavan et al., 1992; Evers and Ellger, 2004; Cope and Baguley, 2009).

Research by Fukunishi et al. (1998a), Schakenraad et al. (2006) and Teunisse and Olde Rikkert (2012) has shown that $\mathrm{MH}$ are more common than previously assumed, with prevalence rates of $3.6 \%$ among groups of patients referred for audiometric testing. Similar to our own experiences, Ross (1978) and Aziz (2009) found that after the publication of an article on the subject several people wrote to them, and told them that they had adjusted to their $\mathrm{MH}$ without seeking any medical attention. However, others show themselves in dire need of medical consultation. MH can indeed be experienced as mild and well-tolerable, but more often they are experienced as severely disabling, leading to impaired quality of life, significant distress, and comorbid anxiety and/or depression. Patients often have difficulty concentrating and falling asleep, and many of them are afraid that they are dementing or otherwise psychiatrically ill (Fukunishi et al., 1998b; Cole et al., 2002; Schakenraad et al., 2006). Occasionally they develop secondary delusions, and accuse others (frequently neighbors) of being responsible for the music. As a result, they may even call the police, move house, or take other drastic measures. Diagnosis and treatment of such cases is paramount, but at this point the lack of treatment protocols and our lack of knowledge about the natural history and prognosis of $\mathrm{MH}$ stand in the way of an evidence-based approach.

Various treatment options have been described in case reports and modest case series. Non-pharmacological treatment tends to consist of lifestyle advice, reassurance, and explanation of the nature of $\mathrm{MH}$, optimization of hearing, and behavioral modifications [such as listening to actual music (Coebergh et al., 2009)], but no previous review has recorded the effectiveness of such interventions. Loneliness may be an important factor and increasing social interactions and conversations can be beneficial.
All pharmacological treatment of idiopathic $\mathrm{MH}$ is off-label. It tends to consist of antiepileptics, antidepressants, antipsychotics or acetylcholinesterase inhibitors, but even when treated for a sufficient amount of time and at adequate plasma levels, $\mathrm{MH}$ can be refractory to most of these treatments (Sacks and Blom, 2012). Repetitive transcranial magnetic stimulation (rTMS) may perhaps be a viable option in the near future, but so far it only showed a favorable response in a single medication-resistant patient with post-traumatic damage to the right temporal lobe (Cosentino et al., 2010).

This review attempts to quantify the treatment as responses described in the literature, and to correlate them with the probable etiology of the $\mathrm{MH}$ at hand. It should be noted, however, that in the literature we reviewed treatment responses were described and defined in widely varying ways. In some papers there was an extensive description of what exactly changed in e.g., the character, loudness and frequency of the $\mathrm{MH}$, whereas other papers only mentioned that they changed, decreased or stopped or remained unaltered. Duration and onset of treatment response were also reported extremely variably and frequently not mentioned at all.

\section{Methods}

For the purpose of this review, we searched the databases of MEDLINE, psycINFO, and Embase Psychiatry for articles matching the terms Music* hallucin*, Musical hallucination, and Treatment, and added relevant papers from our personal collection with titles such as "Auditory Charles Bonnet syndrome" and "The sound of silence." We examined all articles published between 1890 and January 2015 that were written in English, Dutch, French or German.

The variables we assessed in each published case report were age, sex, treatment, and results of treatment. When available, documentation of hearing impairment, electroencephalography (EEG), brain imaging, and psychiatric assessment were used to establish our interpretation of the main etiological factor (which was occasionally different from that of the original authors). Five different etiological groups were distinguished consisting of hypoacusis, brain lesions and other pathology, epilepsy, psychiatric disorder, and intoxication/pharmacology. This classification is modeled on Evers and Ellger's categorization of $\mathrm{MH}$ in 2004 (Evers and Ellger, 2004). When patients had more than one possible etiology, which turned out to be very common, we chose the one most closely linked to the onset of the $\mathrm{MH}$. For example, if a patient with hypoacusis developed a severe depression, and improved after treatment for depression, then psychiatric disorder was selected as the main cause of the $\mathrm{MH}$. However, when the $\mathrm{MH}$ were complicated by depression and did not improve with treatment for depression, than hypoacusis was selected. In two cases no apparent cause was identified (Duncan et al., 1989; Satoh et al., 2007).

All cases were subdivided according to kind of treatment, i.e., non-pharmacological [rTMS, electroconvulsive therapy (ECT), ear-nose-throat intervention, cognitive-behavioral therapy (CBT), coping strategies/explanation], and pharmacological 
[antidepressants, antipsychotics, antiepileptics, other medication (comprising of benzodiazepines and acetylcholinesterase inhibitors), and withdrawal of medication]. Furthermore, we identified cases where the MH decreased or faded away without any treatment, as well as those where it was documented that the patient desired no treatment whatsoever (which could be for multiple reasons, see the Discussion Section).

When $\mathrm{MH}$ appeared soon (i.e., within 1 week) after starting a certain drug or after increasing its dose, and disappeared soon after stopping or reducing the dose, this medication was considered the most likely cause; when patients were occasionally rechallenged and the $\mathrm{MH}$ recurred, this was taken as an extra indication that the medication was causative. However, standardized measures of causality such as the WHO-UMC causality assessment system were not applied. At times there were multiple medications, and at other times the exact time course of the relation between the intoxication/pharmacological intervention and $\mathrm{MH}$ was unclear.

Epilepsy was deemed the main cause when the $\mathrm{MH}$ were phenomenologically linked to a seizure, e.g., as an aura, ictal episode or post-ictal episode, when the patient was treated surgically for an epileptic focus or when epileptiform EEG abnormalities disappeared which had been present prior to treatment.

We scored treatment effects in three groups, i.e., "no effect" (0), "patient experiences a clinically meaningful improvement, but the hallucinations remain" (1), and "complete disappearance of the $\mathrm{MH}^{\prime}$ (2). Improvement was deemed meaningful whenever a report implied that the patient had experienced an improvement in quality of life; irrespective of whether the $\mathrm{MH}$ were experienced as quieter, less frequent, or not interfering as much with sleep or daily activities, or whether there was increased acceptance/insight or improved mood/anxiety. Two articles (Bergman et al., 2014; Islam et al., 2014) used the YaleBrown Obsessive Compulsive Scale (Y-BOCS). At times it was difficult to rate the exact treatment effects; e.g., Warner and Aziz (Warner and Aziz, 2005) briefly described 30 patients, mostly elderly people suffering from hearing loss, and stated that $90 \%$ were treated (among which 23 with antipsychotics). The majority lost the $\mathrm{MH}$ completely, and the remainder reported a reduction in intensity and frequency of the $\mathrm{MH}$. We chose to conservatively document this as a single patient with hearing loss treated with antipsychotics, with a response of 1 . Whenever patients had first tried a certain class of medication without improvement (0), followed by a positive response to another class (1/2), both outcomes were scored.

Author JAFC rated the treatment responses in each report. He is a consultant neurologist who has 9 years of experience with neurological, psychiatric, neurophysiological, and radiological diagnosis, and who personally assessed more than 30 patients experiencing $\mathrm{MH}$. The data were analyzed (and mean treatment response calculated) in Microsoft Excel for Mac 2011.

\section{Results}

A total number of 175 articles were identified that discussed 516 new patients with $\mathrm{MH}$ or related symptoms. This collection of articles included various modest case series [(Fenton and McRae, 1989; Mahendran, 2007), one which described 44 patients with $\mathrm{MH}$ in association with alcohol hallucinosis (Scott, 1975), and one which described 55 patients diagnosed with obsessivecompulsive disorder (OCD) and/or schizophrenia spectrum disorder where the question was asked whether the patient had ever heard music that did not have an external origin (other than humming, thinking of music and simple recollection of music) (Hermesh et al., 2004)].

Among those 175 articles we found 161 that discussed the treatment results of $\mathrm{MH}$ or related symptoms (including some which only discussed whether treatment was desired). No more than 28 of those were published before 1990. We took this as confirmation of the above-mentioned increase in the scientific interest in $\mathrm{MH}$ over the past 25 years rather than as proof of any increase in their prevalence. We then excluded all reports of musical illusions, pseudohallucinations, palinacusis, hypnagogic or hypnopompic hallucinations, and obsessions (i.e., "earworms"); only rarely did our interpretation of obsession vs. hallucination (i.e., "earworm" vs. $\mathrm{MH}$ ) differ from that of the original authors (e.g., Islam et al., 2014). A total number of 276 cases in 147 articles met these inclusion criteria (Colman, 1894; Penfield and Erickson, 1941; David et al., 1944; Mulder and Daly, 1952; Rozanski and Rosen, 1952; Arieff and Brooks, 1958; Rennie, 1964; Ross et al., 1975; Scott, 1975, 1979; Schiffter and Straschill, 1977; Miller and Crosby, 1979; Raghuram et al., 1980; Wieser, 1980; Gilchrist and Kalucy, 1983; Hammeke et al., 1983; Mackworth-Young, 1983; Aizenberg et al., 1986, 1987, 1991; Jonas, 1986; Cambier et al., 1987; Lanska et al., 1987; Patel et al., 1987; Keshavan et al., 1988, 1992; Duncan et al., 1989; Fenton and McRae, 1989; Wengel et al., 1989; Berrios, 1990; McLoughlin, 1990; Donnet and Régis, 1991; Fisman, 1991; Nevins, 1991; Podoll et al., 1991; Shapiro et al., 1991; Vallada and Gentil, 1991; Wagner and Gertz, 1991; Freeland and O’Reilly, 1992; Klostermann et al., 1992; Paquier et al., 1992; Erkwoh et al., 1993; Feehan and Birchwood, 1993; Fénelon et al., 1993; Gilbert, 1993; Inzelberg et al., 1993; Isaacson et al., 1993; Couper, 1994; Hosty, 1994; Murata et al., 1994; Terao, 1995; Wodarz et al., 1995; Baurier and Tuca, 1996; Gertz et al., 1996; Stephane and Hsu, 1996; Douen and Bourque, 1997; Marneros et al., 1997; Thorpe, 1997; Clark, 1998; Fernandez and Crowther, 1998; Fukunishi et al., 1998b, 1999; Terao and Tani, 1998; Baba and Hamada, 1999; Terao and Matsunaga, 1999; Zungu-Dirwayi et al., 1999; David and Fernandez, 2000; Gomibuchi et al., 2000; Iijima et al., 2000; Keeley et al., 2000; Schielke et al., 2000; Augustin et al., 2001; Cerrato et al., 2001; Roberts et al., 2001; Tanriverdi et al., 2001; Ali, 2002; Curtin and Remund, 2002; Evers et al., 2002; Izumi et al., 2002; Assal, 2003; Baba et al., 2003; Brusa et al., 2003; Ginsberg, 2003; Matsui et al., 2003; Moore, 2003; Shinosaki et al., 2003; Stricker and Winger, 2003; Agrawal and Sherman, 2004; Aziz et al., 2004; Fischer et al., 2004; Hageman et al., 2004; Kobayashi et al., 2004; Wilkinson and Schuller, 2004; Davies and Quinn, 2005; Wang, 2005; Biran and Steiner, 2006; Janakiraman et al., 2006; Gentile et al., 2007; Gilhuis et al., 2007; Mahendran, 2007; Satoh et al., 2007; Tomar and Cheung, 2007; Ukai et al., 2007; Allen, 2008; Holroyd and Sabeen, 2008; Mocellin et al., 2008; Umene et al., 2008; Williams et al., 2008; Auffarth and 
Kropp, 2009; Coebergh et al., 2009; Engmann and Reuter, 2009; Ergün et al., 2009; Rentrop et al., 2009; Strauss and Gertz, 2009; Tuerlings et al., 2009; Cosentino et al., 2010; Gondim et al., 2010; Isolan et al., 2010; Kanemura et al., 2010; Mittal and Giron, 2010; Padala et al., 2010; Shoyama et al., 2010; Wong and Bhalerao, 2010; Bleich-Cohen et al., 2011; Huntley et al., 2011; Bhatt and de Carpentier, 2012; Calabrò et al., 2012; Johns and Zuromskis, 2012; Ozsarac et al., 2012; Serrador-García et al., 2012; Simões et al., 2012; Teunisse and Olde Rikkert, 2012; Dinges et al., 2013; Giermanski et al., 2013; Vitorovic and Biller, 2013; Abdel-Aziz and Pomeroy, 2014; Aizawa et al., 2014; Bergman et al., 2014; Colon-Rivera and Oldham, 2014; Futamura et al., 2014; Husain et al., 2014; Islam et al., 2014; Kataoka and Ueno, 2014; Kumar et al., 2014; Mansoor and Ganzini, 2014; Woo et al., 2014; Blom et al., 2015; Joe et al., 2015).

\section{Clinical Features}

The clinical features of those 276 cases are shown in Table 1, and the main etiology in Table 2. Among the cases where sex was stated, women made up $68.2 \%$ of the population. The patients' average age was 63.8 years (range 18-94 years). One hundred and sixty-six of the patients $(60.4 \%)$ had a history of hearing impairment, most of them chronic. The level of hearing impairment-even whether a hearing aid was required and/or used, or which frequencies and/or ear were affected-was often not specified. There was a concomitant psychiatric disorder in $99(36.2 \%)$ of the patients; among them, $69.7 \%$ suffered from mood disorder. Criteria for diagnosing psychiatric disorder were frequently not recorded, and standardized diagnostic methods were rarely used.

\section{Treatment Effects}

In Table 3 the mean treatment effects per etiology and pharmacological class are displayed, as well as the number of patients with a complete response. A mean close to zero indicates no or little effect of the treatment, and a mean close to two indicates that the $\mathrm{MH}$ disappeared completely or almost completely.

TABLE 1 | Clinical features of 276 patient with musical hallucinations.

\begin{tabular}{ll}
\hline Sex $(\boldsymbol{N}=261)$ & Percentage \\
\hline Female $(N=178)$ & $68.2 \%$ \\
Male $(N=83)$ & $31.8 \%$ \\
Age $(N=238)$ & \\
Mean & 63.8 year $(18-94)$ \\
Hearing impairment $(N=166)$ & $60.4 \%$ \\
Psychiatric disorder $(N=99)$ & $36.2 \%$ \\
Depression $(N=52)$ & \\
Other mood disorder $(N=2)$ & \\
Schizophrenia spectrum disorder $(N=18)$ & \\
OCD ( $N=4)$ & \\
Dementia ( $N=6)$ & \\
Anxiety (with or without comorbid depression) $(N=15)$ & \\
Other $(N=2)$ &
\end{tabular}

\section{Hypoacusis}

In the hypoacusis group, 80 out of 96 patients either received treatment or improved spontaneously, with a mean effect of 1.19. Twenty-two patients desired no treatment (in two patients after trying a treatment first) since they generally found that they could manage without. Although impaired hearing was considered the main etiological factor, the group had an average of 1.54 etiological factors. Eleven patients showed spontaneous improvement, often after reassurance. Behavioral interventions that were attempted included improving sleep or lying on one ear at night (which, incidentally, was not helpful during the day) (Keshavan et al., 1992). Several patients report that they were bothered less by their $\mathrm{MH}$ when they listened to the radio (Mahendran, 2007; Teunisse and Olde Rikkert, 2012), drummed along with their fingers (Raghuram et al., 1980), wore headphones (Keshavan et al., 1988), sang along (Berrios, 1990), listened to music at bedtime (Coebergh et al., 2009), rubbed the hair near their ears (Gilchrist and Kalucy, 1983), or used a tinnitus mask (i.e., a hearing device that delivers music-like tones) (Abdel-Aziz and Pomeroy, 2014).

Six patients had some response, and six a complete response to interventions directed at improving their hearing; e.g., (optimizing) hearing aids (e.g., Feehan and Birchwood, 1993; Tuerlings et al., 2009), removing ear wax (Terao and Matsunaga, 1999; Tuerlings et al., 2009), and otosclerosis surgery [which in one case replaced MH with tinnitus (Mocellin et al., 2008)]. $\mathrm{MH}$ occurred only when taking hearing aid out at night in one patient (Serrador-García et al., 2012). It was generally not recorded whether changes in the use of a hearing aid made any difference but several reports mention briefly that no change occurred. Cochlear implantation can be a cause of $\mathrm{MH}$ but in two cases adaptation of the implant did not lead to any meaningful improvement (Auffarth and Kropp, 2009; Joe et al., 2015).

Among the 54 patients treated pharmacologically; on average 1.95 types of medication (range 1-11) were tried. The mean treatment effect of acetylcholinesterase inhibitors was 1.71 in seven patients (Shinosaki et al., 2003; Ukai et al., 2007; Strauss and Gertz, 2009; Serrador-García et al., 2012; Colon-Rivera and Oldham, 2014; Blom et al., 2015). Five other patients were treated with benzodiazepines or barbiturates and their mean response was 0.66 . The mean treatment effect of antidepressants in 19 patients was 1.0, with six showing a complete response. The mean treatment effect of antipsychotics in 31 patients was 0.52 , with

TABLE 2 | Main etiology.

\begin{tabular}{lcc}
\hline Main etiology & N & Percentage (\%) \\
\hline Hypoacusis & 96 & 34.8 \\
Psychiatric disorder & 63 & 22.8 \\
Brain lesion or other pathology & 40 & 14.5 \\
Epilepsy & 12 & 4.4 \\
Intoxication/pharmacology & 63 & 22.8 \\
None of the above & 2 & 0.7 \\
\hline Total & 276 & 100
\end{tabular}


TABLE 3 | Mean effect of (pharmacological) treatment on musical hallucinations $(0=$ no effect, $1=$ clinically meaningful, $2=$ complete disappearance).

\begin{tabular}{|c|c|c|c|c|}
\hline Main etiological factor & Treatment & Mean & $\begin{array}{c}\text { Complete } \\
\text { response } N \\
\text { (\%) }\end{array}$ & $N$ \\
\hline \multirow[t]{5}{*}{ Hypoacusis } & Antipsychotic & 0.52 & $6(19 \%)$ & 31 \\
\hline & Antiepileptic & 0.89 & $6(22 \%)$ & 27 \\
\hline & Antidepressant & 1 & $6(32 \%)$ & 19 \\
\hline & $\begin{array}{l}\text { Acetylcholinesterase } \\
\text { inhibitor }\end{array}$ & 1.71 & $5(71 \%)$ & 7 \\
\hline & $\begin{array}{l}\text { Total response of } \\
\text { all patients }\end{array}$ & 1.19 & $24(32 \%)$ & 76 \\
\hline \multirow[t]{4}{*}{ Psychiatric disorder } & Antipsychotic & 0.75 & $10(28 \%)$ & 36 \\
\hline & Antiepileptic & 1.18 & $4(36 \%)$ & 11 \\
\hline & Antidepressant & 1,18 & $10(45 \%)$ & 22 \\
\hline & Benzodiazepines & 1.00 & $2(40 \%)$ & 5 \\
\hline \multirow[t]{2}{*}{ Psychosis } & Antipsychotics & 1.00 & $6(40 \%)$ & 15 \\
\hline & Total & 1.26 & $8(42 \%)$ & 19 \\
\hline \multirow[t]{4}{*}{ Depression/Anxiety } & Antidepressant & 1.22 & $9(50 \%)$ & 18 \\
\hline & Antipsychotic & 0.67 & $5(21 \%)$ & 24 \\
\hline & Total & 1.32 & $14(36 \%)$ & 39 \\
\hline & $\begin{array}{l}\text { Total response of } \\
\text { all patients }\end{array}$ & 1.25 & $31(49 \%)$ & 63 \\
\hline $\begin{array}{l}\text { Brain lesion or other } \\
\text { pathology }\end{array}$ & $\begin{array}{l}\text { Total response of } \\
\text { all patients }\end{array}$ & 1.66 & $28(70 \%)$ & 40 \\
\hline \multirow[t]{4}{*}{ Intoxication/pharmacology } & Antipsychotic & 0 & & 2 \\
\hline & Antiepileptic & 2.0 & 1 & 1 \\
\hline & Antidepressant & 0 & & 1 \\
\hline & $\begin{array}{l}\text { Total response of } \\
\text { all patients }\end{array}$ & 1.94 & $61(97 \%)$ & 63 \\
\hline
\end{tabular}

six of them achieving a complete response. The mean treatment effect of antiepileptics in 27 patients was 0.89 , with six achieving a complete response.

\section{Psychiatric Disorder}

Among the group diagnosed with a psychiatric disorder (63 patients) many were treated pharmacologically (54 patients). The patients had a mean response to treatment of 1.25 , and an average of 1.65 causes.

One patient benefited from adjustment of his hearing aid, even though psychosis was considered the trigger for his $\mathrm{MH}$ (Keshavan et al., 1992). One benefited from singing along (Miller and Crosby, 1979), one from listening to the radio (Baurier and Tuca, 1996), and one from CBT (Wilkinson and Schuller, 2004). Four patients improved spontaneously and two did not want any intervention even thought there were significantly bothered by their MH (Podoll et al., 1991; Keshavan et al., 1992). Treating the underlying psychiatric disorder with ECT was helpful for $\mathrm{MH}$ in five patients, but not in all (Wengel et al., 1989; Stephane and Hsu, 1996; Janakiraman et al., 2006) and sometimes the effect was temporary (Colon-Rivera and Oldham, 2014).

The pharmacological treatment response was best when an antidepressant was used (1.18) (with 10 of them showing a complete response), or when antiepileptics were used (1.18), with four patients responding completely. Antipsychotics yielded a mean treatment response of 0.75 , and complete disappearance of the $\mathrm{MH}$ in 10 patients. Results tended to be better in patients diagnosed with schizophrenia spectrum disorder (1.00) than in those with mood disorders (0.67). The use of benzodiazepines led to complete disappearance in two patients, and to a mean treatment response of 1.0 (in five patients).

\section{Brain Lesion and Other Pathology}

In the brain lesion and other pathology group (40 patients) the mean number of causes was 1.4 (range 1-3). Sixteen cases of $\mathrm{MH}$ had a cerebrovascular cause, and in nine cases the cause was a tumor and others had pathology like multiple sclerosis and Parkinson's disease. When a tumor was present removal led to disappearance of MH (Penfield and Erickson, 1941; David et al., 1944; Scott, 1979). In all stroke cases, the hallucinations disappeared without any adjuvant treatment in days or months and up to a year [and in one case only ever lasted 90 min (Cerrato et al., 2001)]. In 22 patients $\mathrm{MH}$ disappeared without intervention.

One patient with a previous head trauma, who had not responded to antiepileptics and antidepressants, was treated with rTMS after 1 year of experiencing $\mathrm{MH}$. The MH disappeared after 2 weeks, only to reappear after 4 months; although by that time they were less intense, and only present in a quiet environment and before falling asleep (Cosentino et al., 2010).

All in all it is difficult to fully ascertain any medication effects in the brain injury group. Thirteen patients were treated pharmacologically, but in one case of delirium (Rentrop et al., 2009) and in two cases of brain tumor patients the natural history probably led to improvement (Evers et al., 2002), rather than the use of medication (i.e., olanzapine and pregabalin, respectively). Four patients showed a complete response, and three no response to antiepileptics; three patients were treated with antidepressants, and four with antipsychotics, which are all very small numbers to establish a mean treatment response. Twenty-two improved spontaneously and six did not want any treatment.

\section{Epilepsy}

The rather small epilepsy group, which comprised of 12 patients, had a mean treatment response of 1.66. The mean number of medication used was 1.08 (range 1-4) in eight patients. $\mathrm{MH}$ tended to respond well to antiepileptics or surgery for the underlying cause (Rennie, 1964; Wieser, 1980; Roberts et al., 2001). Four cases of MH resolved spontaneously and were ictal or post-ictal in nature, and some of these patients were on antiepileptics already that was not changed or just started after the seizure but the $\mathrm{MH}$ were in all likelihood post-ictal.

\section{Intoxication/Pharmacology}

The intoxication/pharmacology group comprised of 63 patients. The mean treatment result was a robust 1.94 when patients stopped their medication or switched to another type of medication. When the above-mentioned case series of 44 patients 
with alcoholic hallucinosis (Scott, 1975) was excluded, the mean treatment response was 1.79 . The mean number of causes in the intoxication/pharmacology group was 1.4.

They include benzodiazepines [lormetazepam (Ginsberg, 2003), temazepam (Fisman, 1991), lorazepam (Curtin and Remund, 2002), and triazolam (Nevins, 1991)], opioids [morphine (Davies and Quinn, 2005), tramadol (Keeley et al., 2000) and oxycodone (Moore, 2003)], tricyclic antidepressants [imipramine (Terao, 1995), clomipramine (Vallada and Gentil, 1991) and mirtazapine (Padala et al., 2010)], anticholinergic medication [biperiden (Gertz et al., 1996)], alcohol (Scott, 1975), an N-methyl-D-aspartate antagonist [amantadine (Gondim et al., 2010)], a dopamine agonist [bromocriptine (Kobayashi et al., 2004)], salicylates (Allen, 2008), dipyridamole(Tomar and Cheung, 2007), propranolol (Fernandez and Crowther, 1998), voriconazole (Agrawal and Sherman, 2004), pentoxifylline (Gilbert, 1993) and steroids (Kanemura et al., 2010).

Only six patients in this group were treated with adjuvant medication. This had no effect, except in one patient who suffered from depression, white matter changes and a hearing impairment. Biperiden induced the $\mathrm{MH}$ and they responded to carbamazepine (Gertz et al., 1996). One patient benefited from listening to the radio (Fernandez and Crowther, 1998).

In 42 cases the musical hallucinations decreased or disappeared without any treatment-see Table 4. As indicated above, most of them stemmed from the brain lesion and other pathology group.

\section{Discussion}

Musical hallucinations, like actual musical sounds, are associated with activity in an extensive network of interconnected brain areas. This network comprises auditory areas, visual areas, basal ganglia, brainstem, pons, tegmentum, cerebellum, hippocampi, amygdala, motor cortex, the peripheral auditory system, and possibly many other areas (Sacks and Blom, 2012). Even though there is not a single unique pathophysiological pathway within the network that can be held responsible for the mediation of $\mathrm{MH}$, there is often an etiological factor that would seem to act as a necessary and sufficient condition for it to become activated. We hypothesized that the key to successful treatment of $\mathrm{MH}$ might lie in identifying that etiological factor. Based on our analysis of the treatment results of 276 patients with $\mathrm{MH}$ as described in the literature, the following can be said about this.

TABLE 4 | Decrease or disappearance of musical hallucinations without any intervention.

\begin{tabular}{lr}
\hline Etiological factor & $N$ \\
Hearing impairment & 1 \\
Psychiatric disorder & 4 \\
Brain lesion and other pathology & 22 \\
Epilepsy & 4 \\
None & 1 \\
\hline
\end{tabular}

Total

42
In the hypoacusis group-with patients suffering from idiopathic $\mathrm{MH}$-frequently no treatment is required except for explanation, behavioral interventions, and improving auditory function. And yet pharmacological therapy can also be successful, with many different medications. The mean treatment response rate in this group is highest-although admittedly modest-with acetylcholinesterase inhibitors, followed by antiepileptics and antidepressants, and lowest with antipsychotics (which however can still be useful). Symptomatic $\mathrm{MH}$, on the other hand, are more likely to respond to pharmacological treatment. In the group diagnosed with a psychiatric disorder, the type of disorder provides the most important clue to choice of treatment. Thus, treating $\mathrm{MH}$ experienced in the context of a depression with the aid of an antidepressant is more effective than with an antipsychotic, whereas $\mathrm{MH}$ experienced in the context of a schizophrenia spectrum disorder tend to respond more often to antipsychotics. Patients in the brain-injury and epilepsy groups can best be treated with antiepileptics, although in these groups the natural course of the $\mathrm{MH}$ is often benign, especially after a stroke. When intoxication/pharmacology is the main etiological factor, it is important to stop the medication that is held responsible for their mediation, and if necessary to replace it with a substance from a different pharmacological class.

As an aside, it is worth mentioning that in the intoxication/pharmacology group many causative medications play a role that have an opposite effect to medications used for treatment. Dopamine agonists (causative) and antipsychotics (treatment) work on the same dopaminergic receptors. Anticholinergics and tricyclics (causative) and acetylcholinesterase inhibitors (treatment) act on the same cholinergic neurotransmitters. Benzodiazepines, which act on the gamma-amino-butyric-acid (GABA) system, can at once be causative and curative. This suggests that all the neurotransmitter systems and receptors involved can play an a priori unpredictable role in the mediation and treatment of $\mathrm{MH}$, and that proper clinical and pharmacological assessment is always necessary to establish the course of action that is most likely to yield favorable results.

\section{Limitations}

This review has several limitations. Firstly, there would seem to be a positive publication bias for successful treatments. For example, salicylates (Allen, 2008) and propranolol (Fernandez and Crowther, 1998), which in some studies are associated with the mediation of $\mathrm{MH}$, are used by many of our patients in clinical practice without causing this particular side effect. Moreover, we have attempted to treat some of our patients by withdrawing these medications, and no resolution of the $\mathrm{MH}$ was ever noted. None of the pharmacological treatments (or withdrawal) were ever placebo controlled. There may also be a positive publication bias for pharmacological treatments per se. Many of our patients, after proper explanation, prefer not to try any medication, whereas others try one type of medication but refrain from trying another type. In our experience some patients are content with explanation and practical advice, which is also described by others (Shapiro et al., 1991; Feehan and Birchwood, 1993; Bhatt and de Carpentier, 2012; Johns and Zuromskis, 
2012; Teunisse and Olde Rikkert, 2012). However, the fact that patients show themselves content without any pharmacological intervention does not mean that no treatment should be offered (Podoll et al., 1991; Keshavan et al., 1992).

A second limitation of this review is that its sample size is relatively small $(N=276)$, especially when subdividing the group in etiological subgroups. A previous review included 132 patients (Evers and Ellger, 2004), and yet another one did not state the total number of patients included but instead based its conclusions on 55 relevant papers (Cope and Baguley, 2009). Our sample size is nevertheless the largest analyzed so far. With the small numbers involved it cannot be ruled out that the variations are due to chance since statistical significance of differential treatment responses in every etiological subgroup would often not have been reached.

Thirdly, we may have underestimated the effects of antipsychotics in the hypoacusis group by not including the majority of patients described by Warner and Aziz (2005). As noted above, we decided to count this group as a single patient because individual patient data were lacking in the original report. However, the mean response rate to antipsychotics in this study is much higher than in others. Moreover, by lumping various classes of antidepressants into a single group, we may have missed the opportunity to identify possible group differences, especially since tricyclics are implicated in various studies as possible causes of $\mathrm{MH}$. The same holds true for the various groups of antipsychotics and antiepileptics that work on very different ion channels and neurotransmitters.

If patients have tried multiple drugs in one class but did respond to another one we scored this as a response and therefore overestimated the effect of individual drugs; some patients tried up to 11 medications (Colon-Rivera and Oldham, 2014).

The interpretation of the intoxication/pharmacology literature is influenced by inclusion of 44 patients with alcoholic musical hallucinosis out of a total of 63 patients (Scott, 1975). Removing them from the analysis did not alter the finding that withdrawing the presumed offending medication is highly effective.

\section{Conclusions and Recommendations}

Musical hallucinations are best treated by directing our intervention at the etiological mechanism responsible for their mediation. Based on the findings presented above and on our clinical experience with $\mathrm{MH}$, our advice would be to chart the (possibly multiple) underlying causes with the aid of a history; extensively exploring temporal relationships between $\mathrm{MH}$ and medication, trauma, drug (ab-)use, seizures, and use of hearing aid devices. Furthermore, neurological assessment, psychiatric assessment an ear, nose, and throat (ENT) assessment are recommended, and imaging with an MRI head. Not all patients need treatment, as MH may be self-limiting, especially when occurring after brain lesions. If associated distress is low, reassurance may be enough. When treatment is indicated, we suggest that non-pharmacological interventions should be attempted first. This may involve interventions ranging from behavioral modifications, increasing social interactions and CBT. ENT interventions and withdrawing possible causative medication should be attempted due to their low risk of side effects. When idiopathic $\mathrm{MH}$ significantly affects the patient's quality of life, it is worthwhile to target any particularly troublesome symptom, i.e., anxiety with a selective serotonin reuptake inhibitor (SSRI), a secondary delusion with antipsychotics, and sleep disturbances with hypnotics. In the hypoacusis group, pharmacological treatment can first perhaps best be attempted with acetylcholinesterase inhibitors. Although there currently is only limited evidence for the effectiveness of this medication group, in our clinical experience they can help significantly, while side effects are relatively mild as compared to antipsychotic and antiepileptic medication.

Antidepressants and antiepileptics have a more favorable response rate and less side effects than antipsychotics; considering most patients are elderly. The literature documents several examples of beneficial effects using carbamazepine, often a low doses.

Targeting treatment to the underlying psychiatric disorder can clearly be helpful; $\mathrm{MH}$ in those with mood disorders respond less well to antipsychotics than in those with a psychotic disorder. ECT can clearly be helpful in patients with severe depression and MH (Wengel et al., 1989; Stephane and Hsu, 1996; Janakiraman et al., 2006), albeit sometimes relief of MH is only brief (ColonRivera and Oldham, 2014).

Further exploration of rTMS could be worthwhile after the successful treatment in a very treatment resistant case (Cosentino et al., 2010).

Finally, we would like to make recommendations for further research. There ought to be a clear documentation of the volume and frequency of the $\mathrm{MH}$, degree of control over the $\mathrm{MH}$, quality of the $\mathrm{MH}$ (as well as its relation to tinnitus), and the influence of $\mathrm{MH}$ on daily life, before and after the start of treatment. Documenting what is taken as a successful treatment response (i.e., less meaningful, less frequent/intrusive/loud, more control, complete disappearance, improved sleep) is also essential. It should be considered to try placebo-controlled treatment (and withdrawal of presumed offending medication). Larger sized treatment trials should be able to elucidate whether the differential treatment response to different (classes) of medication is real, as suggested by this review. This should allow for a more effective and accurate assessment of the effects of treatment in the future. Perhaps, analogous to recent initiatives to create international databases for rare diseases, a database for cases of $\mathrm{MH}$ should be considered, with a focus on diagnostic findings, natural course, and treatment results.

\section{Author Contributions}

JC designed the manuscript, acquired data, drafted the manuscript, gave final approval of the version to be published, and agreed to be accountable for all aspects of the work in ensuring that questions related to the accuracy or integrity of any part of the work are appropriately investigated and resolved. RL contributed substantially to the design of the manuscript, acquired data, revised the manuscript, gave final approval of the version to be published, and agreed to be accountable for all aspects of the work in ensuring that questions 
related to the accuracy or integrity of any part of the work are appropriately investigated and resolved. RB acquired data, helped to draft the manuscript, revised the manuscript, gave final approval of the version to be published, and agreed to be accountable for all aspects of the work in ensuring that questions related to the accuracy or integrity of any part of the work are appropriately investigated and resolved. IS contributed substantially to the design of the manuscript, revised the manuscript, gave final approval of the version to be published,

\section{References}

Abdel-Aziz, K., and Pomeroy, I. (2014). Ear worms and auditory Charles Bonnet syndrome. J. Neurol. Neurosurg. Psychiatr. 85, e4. doi: 10.1136/jnnp-2014309236.80

Agrawal, A. K., and Sherman, L. K. (2004). Voriconazole-induced musical hallucinations. Infection 32, 293-295. doi: 10.1007/s15010-004-3121-1

Aizawa, S., Terao, T., Hatano, K., and Ishii, N. (2014). Musical hallucinations responding to a further increase of carbamazepine. BMJ Case Rep. 2014:bcr2014206418. doi: 10.1136/bcr-2014-206418

Aizenberg, D., Dorfman-Etrog, P., Zemishlany, Z., and Hermesh, H. (1991). Musical hallucinations and hearing deficit in a young non-psychotic female. Psychopathology 24, 45-48. doi: 10.1159/000284696

Aizenberg, D., Modai, I., Roitman, M., Mendelson, E., and Wijsenbeek, H. (1987). Musical hallucinations, depression and old age. Psychopathology 20, 220-223. doi: 10.1159/000284502

Aizenberg, D., Schwartz, B., and Modai, I. (1986). Musical hallucinations, acquired deafness, and depression. J. Nerv. Ment. Dis. 174, 309-311. doi: 10.1097/00005053-198605000-00008

Ali, J. A. (2002). Musical hallucinations and deafness: a case report and review of the literature. Neuropsychiatry Neuropsychol. Behav. Neurol. 15, 66-70.

Allen, J. R. (2008). The woman who heard music: high salicylate levels and tinnitus. Minn. Med. 91, 44-45.

Arieff, A., and Brooks, J. (1958). Musical hallucinations as a psychical seizure: focal epileptic disorder. Q. Bull. Northwest. Univ. Med. Sch. 32, 201-203.

Assal, F. (2003). Musical hallucinations in the elderly. Rev. Med. Suisse Romande. $123,41-44$.

Auffarth, I. S., and Kropp, S. (2009). Musical hallucination in a patient after cochlear implantation. J. Neuropsychiatry Clin. Neurosci. 21, 230-231. doi: 10.1176/jnp.2009.21.2.230

Augustin, J., Guegan-Massardier, E., Levillain, D., Lemarchand, M., Mihout, B., and Hannequin, D. (2001). Musical hallucinosis following infarction of the right middle cerebral artery. Rev. Neurol. 157, 289-292.

Aziz, V. (2009). Musical hallucinations in normal children and adult non-psychiatric population. BMJ Case Rep. 2009:bcr06.2008.0023. doi: $10.1136 /$ bcr.06.2008.0023

Aziz, V. M., Nessim, M., and Warner, N. J. (2004). Charles-Bonnet syndrome and musical hallucination. Int. Psychogeriatr. 80, 489-491. doi: $10.1017 /$ S1041610204220919

Baba, A., and Hamada, H. (1999). Musical hallucinations in schizophrenia. Psychopathology 32, 242-251. doi: 10.1159/000029096

Baba, A., Hamada, H., and Kocha, H. (2003). Musical hallucinations in schizophrenia: 2. Relations with verbal hallucinations. Psychopathology 36, 104-110. doi: 10.1159/000070366

Baurier, V. O., and Tuca, J. O. (1996). Auditory hallucinosis in brainstem lesions and musical hallucination in deafness. Analogies and differences. Eur. J. Neurol. 3, 203-211. doi: 10.1111/j.1468-1331.1996.tb00424.x

Bergman, J., Pashinian, A., Weizman, A., and Poyurovsky, M. (2014). The beneficial effect of escitalopram on obsessive-compulsive-related musical hallucinations in elderly patients with hearing impairment. Int. Clin. Psychopharmacol. 29, 263-265. doi: 10.1097/YIC.00000000000 00037

Berrios, G. E. (1990). Musical hallucinations. A historical and clinical study. Br. J. Psychiatry 156, 188-194. doi: 10.1192/bjp.156.2.188 and agreed to be accountable for all aspects of the work in ensuring that questions related to the accuracy or integrity of any part of the work are appropriately investigated and resolved. JB contributed substantially to the design of the manuscript, revised the manuscript, gave final approval of the version to be published, and agreed to be accountable for all aspects of the work in ensuring that questions related to the accuracy or integrity of any part of the work are appropriately investigated and resolved.

Bhatt, Y. M., and de Carpentier, J. P. (2012). Musical hallucination following whiplash injury: case report and literature review. J. Laryngol. Otol. 126, 615-618. doi: 10.1017/S0022215112000242

Biran, I., and Steiner, I. (2006). Abnormal musical pacemaker in a patient with musical hallucinations. Eur. J. Neurol. 13, 1378-1380. doi: 10.1111/j.14681331.2006.01470.x

Bleich-Cohen, M., Hendler, T., Pashinian, A., Faragian, S., and Poyurovsky, M. (2011). Obsessive musical hallucinations in a Schizophrenia patient: psychopathological and fMRI characteristics. CNS Spectr. 16, 153-156. doi: 10.1017/S1092852912000326

Blom, J. D., Coebergh, J. A. F., Lauw, R., and Sommer, I. E. C. (2015). Musical hallucinations treated with acetylcholinesterase inhibitors. Front. Psychiatry 6:46. doi: 10.3389/fpsyt.2015.00046

Brusa, L., Panella, M., Koch, G., Bernardi, G., and Massa, R. (2003). Hashimoto's encephalopathy presenting with musical hallucinosis. J. Neurol. 250, 627-628. doi: 10.1007/s00415-003-1058-4

Calabrò, R. S., Baglieri, A., Ferlazzo, E., Passari, S., Marino, S., and Bramanti, P. (2012). Neurofunctional assessment in a stroke patient with musical hallucinations. Neurocase 18, 514-520. doi: 10.1080/13554794.2011.633530

Cambier, J., Decroix, J. P., and Masson, C. (1987). Auditory hallucinations in lesions of the brain stem. Rev. Neurol. (Paris). 143, 255-262.

Cerrato, P., Imperiale, D., Giraudo, M., Baima, C., Grasso, M., Lopiano, L., et al. (2001). Complex musical hallucinosis in a professional musician with a left subcortical haemorrhage. J. Neurol. Neurosurg. Psychiatry 71, 280-281. doi: 10.1136/jnnp.71.2.280

Clark, J. (1998). Case history of a patient with musical hallucinations and Parkinson's disease. Int. J. Geriatr. Psychiatry 13, 886-887.

Coebergh, J. A. F., Shaya, M., Koopman, J. P., and Blom, J. D. (2009). [Musical hallucinations]. Ned. Tijdschr. Geneeskd. 153, 862-865.

Cole, M. G., Dowson, L., Nandini, D., and Belzile, E. (2002). The prevalence and phenomenology of auditory hallucinations among elderly subjects attending an audiology clinic. Int. J. Geriatr. Psychiatry 17, 444-452. doi: 10.1002/gps.618

Colman, W. S. (1894). Hallucinations in the Sane, associated with local organic disease of the sensory organs, etc. Br. Med. J. 1, 1015-1017. doi: 10.1136/bmj.1.1741.1015

Colon-Rivera, H. A., and Oldham, M. A. (2014). The mind with a radio of its own: a case report and review of the literature on the treatment of musical hallucinations. Gen. Hosp. Psychiatry 36, 220-224. doi: 10.1016/j.genhosppsych.2013.10.021

Cope, T. E., and Baguley, D. M. (2009). Is musical hallucination an otological phenomenon? a review of the literature. Clin. Otolaryngol. 34, 423-430. doi: 10.1111/j.1749-4486.2009.02013.x

Cosentino, G., Giglia, G., Palermo, A., Panetta, M. L., Lo Baido, R., Brighina, F., et al. (2010). A case of post-traumatic complex auditory hallucinosis treated with rTMS. Neurocase 16, 267-272. doi: 10.1080/13554790903456191

Couper, J. (1994). Unilateral musical hallucinations and all that jazz. Aust. N.Z. J. Psychiatry 28, 516-519. doi: 10.3109/00048679409075882

Curtin, F., and Remund, C. (2002). Musical hallucinations during a treatment with benzodiazepine [6]. Can. J. Psychiatry 47, 789-790.

David, M. M., Hecaen, H., and Coulonjou, R. (1944). Hallucination auditives sans delire par affections neurologiques. Ann. Med. Psychol. 102, 139-143.

David, R. R., and Fernandez, H. H. (2000). Quetiapine for hypnogogic musical release hallucinations. J. Geriatr. Psychiatry Neurol. 13, 210-211. doi: $10.1177 / 089198870001300406$ 
Davies, A. N., and Quinn, T. (2005). Opioid-related musical hallucinations. J. Pain Symptom Manage. 29, 327-328. doi: 10.1016/j.jpainsymman.2005.02.003

Dinges, M., Riemer, T., Schubert, T., and Prüss, H. (2013). Musical hallucinations after pontine ischemia: the auditory Charles Bonnet syndrome? J. Neurol. 260, 2678-2680. doi: 10.1007/s00415-013-7114-9

Donnet, A., and Régis, H. (1991). Musical hallucinations. Rev. Med. Interne. 12, 303-305. doi: 10.1016/S0248-8663(05)82869-3

Douen, A. G., and Bourque, P. R. (1997). Musical auditory hallucinosis from Listeria rhombencephalitis. Can. J. Neurol. Sci. 24, 70-72.

Duncan, R., Mitchell, J. D., and Critchley, E. M. R. (1989). Hallucinations and music. Behav. Neurol. 2, 115-124.

Engmann, B., and Reuter, M. (2009). Spontaneous perception of melodies hallucination or epilepsy? Nervenheilkunde 28, 217-221.

Ergün, U., Bozbaş, A., Akin, U., and Inan, L. (2009). Musical hallucinations and Parkinson disease. Neurologist 15, 150-152. doi: 10.1097/NRL.0b013e3181872da7

Erkwoh, R., Ebel, H., Kachel, F., Reiche, W., Ringelstein, E. B., Büll, U., et al. (1993). 18FDG-PET and electroencephalographic findings in a patient suffering from musical hallucinations. NuklearMedizin 32, 159-163.

Evers, S., and Ellger, T. (2004). The clinical spectrum of musical hallucinations. J. Neurol. Sci. 227, 55-65. doi: 10.1016/j.jns.2004.08.004

Evers, S., Ellger, T., Ringelstein, E. B., and Knecht, S. (2002). Is hemispheric language dominance relevant in musical hallucinations? Two case reports. Eur. Arch. Psychiatry Clin. Neurosci. 252, 299-302. doi: 10.1007/s00406-002-0396-z

Feehan, C. J., and Birchwood, M. (1993). A case of monosymptomatic musical hallucinations. Ir. J. Psychol. Med. 10, 89-90.

Fénelon, G., Marie, S., Ferroir, J. P., and Guillard, A. (1993). Musical hallucinations: 7 cases. Rev. Neurol. 149, 462-467.

Fenton, G. W., and McRae, D. A. (1989). Musical hallucinations in a deaf elderly woman. Br. J. Psychiatry 155, 401-403.

Fernandez, A., and Crowther, T. R. V. W. (1998). Musical hallucinations induced by propranolol. J. Nerv. Ment. Dis.. 186, 192-194. doi: 10.1097/00005053199803000-00010

Fischer, C. E., Marchie, A., and Norris, M. (2004). Musical and auditory hallucinations: a spectrum. Psychiatry Clin. Neurosci. 58, 96-98. doi: 10.1111/j.1440-1819.2004.01200.x

Fisman, M. (1991). Musical hallucinations: report of two unusual cases. Can. J. Psychiatry. 36, 609-611.

Freeland, A., and O'Reilly, R. (1992). Musical hallucinations: another case report. Can. J. Psychiatry 37:731.

Fukunishi, I., Horikawa, N., and Onai, H. (1998a). Prevalence rate of musical hallucinations in a general hospital setting. Psychosomatics 39:175. doi: 10.1016/S0033-3182(98)71368-4

Fukunishi, I., Kitaoka, T., Shirai, T., and Watanabe, S. (1998b). Musical hallucinations after childbirth in a female patient on hemodialysis. Nephron 79:105.

Fukunishi, I., Kita, Y., Hariharia, Y., Kubota, K., Takayama, T., Kawarasaki, H., et al. (1999). Musical hallucinations after living-donor liver transplantation. Psychosomatics 40, 531. doi: 10.1016/S0033-3182(99)71198-9

Futamura, A., Katoh, H., and Kawamura, M. (2014). [Successful treatment with anti-epileptic-drug of an 83-year-old man with musical hallucinosis]. Brain Nerve 66, 599-603.

Gentile, S., Ferrero, M., Giudice, R. L., Rainero, I., and Pinessi, L. (2007). Abdominal pain associated with musical hallucinations: a case report. Eur. J. Neurol. 14, e7-e8. doi: 10.1111/j.1468-1331.2007.01944.x

Gertz, H. J., Göhringer, K., and Schimmelpfennig, C. (1996). Successful carbamazepine therapy of 2 cases of music hallucinations. Nervenarzt 67, 387-389.

Giermanski, J., Bastiampillai, T., Gupta, A. (2013). "I"ve got an iPod in my head'. Aust N.Z. J. Psychiatry 47, 963-964. doi: 10.1177/0004867413482010

Gilbert, G. J. (1993). Pentoxifylline-induced musical hallucinations. Neurology 43, 1621-1622. doi: 10.1212/WNL.43.8.1621

Gilchrist, P. N., and Kalucy, R. S. (1983). Musical hallucinations in the elderly: a variation on the theme. Aust. N.Z. J. Psychiatry 17, 286-287. doi: $10.3109 / 00048678309161286$

Gilhuis, H. J., Dara Hama-Amin, A., and Renier, W. (2007). Songs from childhood in the head. Clin. Otolaryngol. 32, 419-420. doi: 10.1111/j.17494486.2007.01515.x
Ginsberg, D. L. (2003). Benzodiazepine-associated musical hallucinations. Prim. psychiatry 10, 21-22.

Gomibuchi, T., Gomibuchi, K., Akiyama, T., Tsuda, H., and Hayakawa, T. (2000). Obsession of hearing music: from the viewpoint of Morita theory. Psychiatry Clin. Neurosci. 54, 203-206. doi: 10.1046/j.1440-1819.2000. 00659. $\mathrm{x}$

Gondim, F. A., Costa, H. A., Taunay, T. C., de Oliveira, G. R., Ferreira, J. M., and Rola, F. H. (2010). Transient amantadine-induced musical hallucinations in a patient with Parkinson's disease. Mov. Disord. 25, 1505-1506. doi: $10.1002 / \mathrm{mds} .22553$

Hageman, G., Wagener-Schimmel, L., Nijhuis, I., and Vink, A. (2004). Liedjes in het hoofd: het syndroom van Oliver Sacks. Tijdschr. Neurol. Neurochir. 105, 26-31.

Hammeke, T. A., McQuillen, M. P., and Cohen, B. A. (1983). Musical hallucinations associated with acquired deafness. J. Neurol. Neurosurg. Psychiatry 46, 570-572. doi: 10.1136/jnnp.46.6.570

Hermesh, H., Konas, S., Shiloh, R., Dar, R., Marom, S., Weizman, A., et al. (2004). Musical hallucinations: prevalence in psychotic and nonpsychotic outpatients. J. Clin. Psychiatry 65, 191-197. doi: 10.4088/JCP.v65n0208

Holroyd, S., and Sabeen, S. (2008). Successful treatment of hallucinations associated with sensory impairment using gabapentin. J. Neuropsychiatry Clin. Neurosci. 20, 364-366. doi: 10.1176/jnp.2008.20.3.364

Hosty, G. (1994). Musical hallucinosis: auditory Cherles Bonnet syndrome? Ir. J. Psychol. Med. 11:29.

Huntley, J. D., Sandall, A., and Philpot, M. (2011). "In the midnight hour": a case report of musical hallucinations with multiple etiological factors treated with lamotrigine. Int. Psychogeriatry. 23, 322-324. doi: 10.1017/S104161021 0001997

Husain, F., Levin, J., Scott, J., and Fjeldstad, C. (2014). Recurrent refrains in a patient with multiple sclerosis: earworms or musical hallucinations? Mult. Scler. Relat. Disord. 3, 276-278. doi: 10.1016/j.msard.2013.08.004

Iijima, M., Maeda, T., Tshubouchi, K., Sano, K., and Iwamoto, J. (2000). Musical hallucinations with post- pharyngolaryngoesophagectomyaphonia. Gen. Hosp. Psychiatry 22, 135-136. doi: 10.1016/S0163-8343(99)00050-X

Inzelberg, R., Vishnievskaya, S., and Korczyn, A. D. (1993). Transient musical hallucinosis. J. Neurol. Neurosurg. Psychiatry. 56:833. doi: 10.1136/jnnp.56.7.833

Isaacson, S. H., Carr, J., and Rowan, A. J. (1993). Ciprofloxacin-induced complex partial status epilepticus manifesting as an acute confusional state. Neurology 43, 1619-1621.

Islam, L., Scarone, S., and Gambini, O. (2014). Obsessive-compulsive disorder presenting with musical obsessions in otosclerosis: a case report. J. Med. Case Rep. 8:384. doi: 10.1186/1752-1947-8-384

Isolan, G. R., Bianchin, M. M., Bragatti, J. A., Torres, C., and Schwartsmann, G. (2010). Musical hallucinations following insular glioma resection. Neurosurg. Focus 28:E9. doi: 10.3171/2009.12.FOCUSFOCUS09243

Izumi, Y., Terao, T., Ishino, Y., and Nakamura, J. (2002). Differences in regional cerebral blood flow during musical and verbal hallucinations. Psychiatry Res. 116, 119-123. doi: 10.1016/S0925-4927(02)00083-5

Janakiraman, R., Wildgoose, K., and Seelam, K. (2006). ECT associated musical hallucinations in an elderly patient: a case report. Ann. Gen. Psychiatry 5:10. doi: $10.1186 / 1744-859 \mathrm{X}-5-10$

Joe, S., Park, J., Lim, J., and Park, C. (2015). Unilateral musical hallucination after a hybrid cochlear implantation. Gen. Hosp. Psychiatry 37, 97.e1-97.e3. doi: 10.1016/j.genhosppsych.2014.09.014

Johns, C., and Zuromskis, T. (2012). The sound of silence. Lancet 380:1712. doi $10.1016 / \mathrm{S} 0140-6736(12) 61331-2$

Jonas, W. R. (1986). [Auditory hallucinations in hearing loss. Case report]. Nervenarzt 57, 252-254.

Kanemura, S., Tanimukai, H., and Tsuneto, S. (2010). Can "steroid switching" improve steroid-induced musical hallucinations in a patient with terminal cancer? J. Palliat. Med. 13, 1495-1498. doi: 10.1089/jpm.2010.9751

Kataoka, H., and Ueno, S. (2014). Auditory musical hallucinations associated with extended-release pramipexole in an elderly patient with Parkinson's disease. Medicine (Baltimore) 93:e251. doi: 10.1097/MD.0000000000000251

Keeley, P. W., Foster, G., and Whitelaw, L. (2000). Hear my song: auditory hallucinations with tramadol hydrochloride. Br. Med. J. 321:1608. doi: $10.1136 / \mathrm{bmj} .321 .7276 .1608$ 
Keshavan, M. S., David, A. S., Steingard, S., and Lishman, W. A. (1992). Musical hallucinations: a review and synthesis. Neuropsychiatry Neuropsychol. Behav. Neurol. 5, 211-223.

Keshavan, M. S., Kahn, E. M., and Brar, J. S. (1988). Musical hallucinations following removal of a right frontal meningioma. J. Neurol. Neurosurg. Psychiatry 51:1235. doi: 10.1136/jnnp.51.9.1235

Klostermann, W., Vieregge, P., and Kömpf, D. (1992). Musical pseudohallucination in acquired hearing loss. Fortschr. Neurol. Psychiatry 60, 262-273. doi: 10.1055/s-2007-999146

Kobayashi, T., Miyata, Y., Okamoto, S., and Kato, S. (2004). Musical hallucinations induced by bromocriptine. Psychogeriatrics 4, 102-106. doi: 10.1111/j.14798301.2004.00056.x

Kumar, S., Sedley, W., Barnes, G. R., Teki, S., Friston, K. J., and Griffiths, T. D. (2014). A brain basis for musical hallucinations. Cortex 52, 86-97. doi: 10.1016/j.cortex.2013.12.002

Lanska, D. J., Lanska, M. J., and Mendez, M. F. (1987). Brainstem auditory hallucinosis. Neurology 37:1685.

Mackworth-Young, C. G. (1983). Sequential musical symptoms in a professional musician with presumed encephalitis. Cortex 19, 413-419.

Mahendran, R. (2007). The psychopathology of musical hallucinations. Singapore Med. J. 48:e68.

Mansoor, D., and Ganzini, L. (2014). Musical hallucinations successfully treated with antipsychotic medications: three case reports. Psychosomatics 55, 191-193. doi: 10.1016/j.psym.2013.02.004

Marneros, A., Beyenburg, S., and Berghaus, A. (1997). Unilateral hallucinations and other psychotic symptoms due to otosclerosis. Psychopathology 30, 89-92. doi: $10.1159 / 000285034$

Matsui, T., Matsunaga, H., Ohya, K., Iwasaki, Y., Koshimune, K., Miyata, A., et al. (2003). Clinical features in two cases with musical obsessions who successfully responded to clomipramine. Psychiatry Clin. Neurosci.57, 47-51. doi: 10.1046/j.1440-1819.2003.01078.x

McLoughlin, I. (1990). Musical hallucinations. Br. J. Psychiatry 156:452.

Miller, T. C., and Crosby, T. W. (1979). Musical hallucinations in a deaf elderly Patient 5, 301-302.

Mittal, M., and Giron, L. T. (2010). Elvis is back: musical hallucinations in a Parkinson disease patient. South. Med. J. 103, 837-841. doi: 10.1097/SMJ.0b013e3181e63204

Mocellin, R., Walterfang, M., and Velakoulis, D. (2008). Musical hallucinosis: case reports and possible neurobiological models. Acta Neuropsychiatry 20, 91-95. doi: 10.1111/j.1601-5215.2007.00255.x

Moore, T. A. (2003). Musical hallucinations induced by oxycodone. Am. J.Geriatr. Psychiatry 11:470.

Mulder, D. W., and Daly, D. (1952). Psychiatric symptoms associated with lesions of temporal lobe. J. Am. Med. Assoc. 150, 173. doi: 10.1001/jama.1952.03680030005003

Murata, S., Naritomi, H., and Sawada, T. (1994). Musical auditory hallucinations caused by a brainstem lesion. Neurology 44, 156-158. doi: 10.1212/WNL.44.1.156

Nevins, M. A. (1991). Musical hallucinations and triazolam use. N.J. Med. 88, 907-908.

Ozsarac, M., Aksay, E., Kiyan, S., Unek, O., and Gulec, F. F. (2012). De novo cerebral arteriovenous malformation: pink Floyd's song "brick in the Wall" as a warning sign. J. Emerg. Med. 43, e17-e20. doi: 10.1016/j.jemermed.2009.05.035

Padala, K. P., Padala, P. R., Malloy, T., and Burke, W. J. (2010). New onset multimodal hallucinations associated with mirtazapine: a case report. Int. Psychogeriatr. 22, 837-839. doi: 10.1017/S1041610210000554

Paquier, P., van Vugt, P., Bal, P., Cras, P., Parizel, P. M., van Haesendonck, J., et al. (1992). Transient musical hallucinosis of central origin: a review and clinical study. J. Neurol. Neurosurg. Psychiatry 55, 1069-1073. doi: 10.1136/jnnp.55.11.1069

Patel, H. C., Keshavan, M. S., and Martin, S. (1987). A case of Charles Bonnet syndrome with musical hallucinations. Can. J. Psychiatry 32, 303-304.

Penfield, W., and Erickson, T. C. (1941). Epilepsy and Cerebral Localization. London: Bailliere, Tindall and Cox.

Podoll, K., Thilmann, A. F., and Noth, J. (1991). Musical hallucinations in hearing loss in the aged. Nervenarzt 62, 451-453.

Raghuram, R., Keshavan, M. D., and Channabasavanna, S. M. (1980). Musical hallucinations in a deaf middle-aged patient. J. Clin. Psychiatry 41:357.
Rennie, I. D. (1964). Musical hallucinations associated with epilepsy. Guys Hosp. Rep. 143-152.

Rentrop, M., Knebel, C., and Förstl, H. (2009). Opera-hallucinosis. Int. J. Geriatr. Psychiatry 24, 432-433. doi: 10.1002/gps.2124

Roberts, D. L., Tatini, U., Zimmerman, R. S., Bortz, J. J., and Sirven, J. I. (2001). Musical hallucinations associated with seizures originating from an intracranial aneurysm. Mayo Clin. Proc. 76, 423-426. doi: 10.1016/S0025-6196(11)62391-4

Ross, E. D. (1978). Musical hallucinations in deafness revisited. JAMA 240:1716.

Ross, E. D., Jossman, P. B., Bell, B., Sabin, T., and Geschwind, N. (1975). Muscial hallucinations in deafness. JAMA 231, 620-622. doi: 10.1001/jama.1975.03240180056018

Rozanski, J., and Rosen, H. (1952). Musical hallucinosis in otosclerosis. Confin. Neurol. 12, 49-54. doi: 10.1159/000105768

Sacks, O., and Blom, J. D. (2012). "Musical hallucinations," in Hallucinations Research and Practice, eds J. D. Blom and I. E. C. Sommer (New York, NY: Springer), 133-42.

Satoh, M., Kokubo, M., and Kuzuhara, S. (2007). A case of idiopathic musical hallucination with increasing repertoire. J. Neurol. Neurosurg. Psychiatr. 78, 203-204. doi: 10.1136/jnnp.2006.100313

Schakenraad, S. M. M., Teunisse, R. J., and Olde Rikkert, M. G. (2006). Musical hallucinations in psychiatric patients. Int. J. Geriatr. Psychiatry 21, 394-397. doi: 10.1002 /gps. 1463

Schielke, E., Reuter, U., Hoffmann, O., and Weber, J. R. (2000). Musical hallucinations with dorsal pontine lesions. Neurology 55, 454-455. doi: 10.1212/WNL.55.3.454

Schiffter, R., and Straschill, M. (1977). [Case report of a patient with sensory status epilepticus]. Nervenarzt 48, 321-325.

Scott, M. (1979). Musical hallucinations from meningioma. JAMA 241, 1683. doi: 10.1001/jama.1979.03290420011006

Scott, R. T. (1975). Hallucinations of music in alcohol withdrawal. Neurology 25:362.

Serrador-García, M., Santos-Bueso, E., Sáenz-Francés, F., Díaz-Valle, D., MartínezDe-La-Casa-Borrelia, J. M., and García-Feijóo, J. (2012). Charles Bonnet plus syndrome: apropos of a case. Eur. J. Ophthalmol. 22, 836-839. doi: 10.5301/ejo.5000130

Shapiro, C. M., Kasem, H., and Tewari, S. (1991). My music-a case of musical reminiscence diagnosed courtesy of the BBC. J. Neurol. Neurosurg. Psychiatr. 54, 88-89. doi: 10.1136/jnnp.54.1.88-a

Shinosaki, K., Yamamoto, M., Ukai, S., Kawaguchi, S., Ogawa, A., Ishii, R., et al. (2003). Desynchronization in the right auditory cortex during musical hallucinations: a MEG study. Psychogeriatrics 3, 88-92. doi: 10.1046/j.14798301.2003.00009.x

Shoyama, M., Ukai, S., Kitabata, Y., Yamamoto, M., Okumura, M., Kose, A., et al. (2010). Evaluation of regional cerebral blood flow in a patient with musical hallucinations. Neurocase 16, 1-6. doi: 10.1080/13554790903070265

Simões, S., Mesquita, J., Marçal, N., and Santos, M. (2012). Musical hallucinations: case report and review of the literature. J. Neuropsychiatry Clin. Neurosci. 24:E8. doi: 10.1176/appi.neuropsych.11050107

Stephane, M., and Hsu, L. K. (1996). Musical hallucinations: interplay of degenerative brain disease, psychosis, and culture in a Chinese woman. J. Nerv. Ment. Dis. 184, 59-61. doi: 10.1097/00005053-199601000-00012

Strauss, M., and Gertz, H.-J. (2009). Treatment of musical hallucinosis with acetylcholinesterase inhibitors. J. Neurol. Neurosurg. Psychiatr. 16, 1298-1299. doi: 10.1136/jnnp.2008.160978

Stricker, R. B., and Winger, E. E. (2003). Musical hallucinations in patients with Lyme disease. South. Med. J. 96, 711-715. doi: 10.1097/01.SMJ.0000053458.21691.2E

Tanriverdi, N., Sayilgan, M. A., and Ozçürümez, G. (2001). Musical hallucinations associated with abruptly developed bilateral loss of hearing. Acta Psychiatr. Scand.103, 153-155. doi: 10.1034/j.1600-0447.2001.00169.x

Terao, T. (1995). Tricyclic-induced musical hallucinations and states of relative sensory deprivation. Biol. Psychiatry 38, 192-193. doi: 10.1016/00063223(95)00058-O

Terao, T., and Matsunaga, K. (1999). Musical hallucinations and palinacousis. Psychopathology 32, 57-59. doi: 10.1159/000029068

Terao, T., and Tani, Y. (1998). Carbamazepine treatment in a case of musical hallucinations with temporal lobe abnormalities. Aust. N.Z. J. Psychiatry 32, 454-456. doi: 10.3109/00048679809065540 
Teunisse, R. J., and Olde Rikkert, M. G. (2012). Prevalence of musical hallucinations in patients referred for audiometric testing. Am. J. Geriatr. Psychiatry 20, 1075-1077. doi: 10.1097/JGP.0b013e3182 $3 \mathrm{e} 31 \mathrm{c} 4$

Thorpe, L. (1997). The treatment of psychotic disorders in late life. Can. J. Psychiatry 42(Suppl. 1), 19S-27S.

Tomar, A., and Cheung, G. (2007). Musical hallucinations induced by drugs. Int. Psychogeriatr. 19, 1169-1172. doi: 10.1017/S1041610207005820

Tuerlings, J. H., Wijnen, H., Boerman, R., and Verwey, B. (2009). Music as an uninvited guest: the auditive variant of the Charles Bonnet syndrome. Tijdschr. Psychiatr. 51, 853-858.

Ukai, S., Yamamoto, M., Tanaka, M., Shinosaki, K., and Takeda, M. (2007). Donepezil in the treatment of musical hallucinations. Psychiatry Clin. Neurosci. 61, 190-192. doi: 10.1111/j.1440-1819.2007.01636.x

Umene, W., Yoshimura, R., Hori, H., and Nakamura, J. (2008). A case of vascular depression associated with musical hallucinations successfully treated with paroxetine and a low dose of risperidone. Psychogeriatrics 8, 38-41. doi: 10.1111/j.1479-8301.2007.00209.x

Vallada, H. P., and Gentil, V. (1991). Musical hallucinations triggered by clomipramine? Br. J. Psychiatry 159, 888-889. doi: 10.1192/bjp. 159.6.888

Vitorovic, D., and Biller, J. (2013). Musical hallucinations and forgotten tunes - case report and brief literature review. Front. Neurol. 4:109. doi: 10.3389/fneur.2013.00109

Wagner, S., and Gertz, H. (1991). Musikalische halluzinationen bei scherhorigkeitfallbericht. Z. Gerontopsychol. Psychiatrie 4, 89-193.

Wang, E. (2005). A case of musical hallucinations. Clin. Geriatr. 13, 11-13.

Warner, N., and Aziz, V. (2005). Hymns and arias: musical hallucinations in older people in Wales. Int. J. Geriatr. Psychiatry 20, 658-660. doi: 10.1002/gps.1338

Wengel, S. P., Burke, W. J., and Holemon, D. (1989). Musical hallucinations. The sounds of silence? J. Am. Geriatr. Soc. 37, 163-166. doi: 10.1111/j.15325415.1989.tb05877.x
Wieser, H. G. (1980). Temporal lobe or psychomotor status epilepticus. A case report. Electroencephalogr. Clin. Neurophysiol. 48, 558-572. doi: 10.1016/00134694(80)90291-6

Wilkinson, P., and Schuller, S. (2004). Late-onset auditory hallucinations treated with cognitive behaviour therapy. Int. J. Geriatr. Psychiatry 19, 598-599. doi: 10.1002 /gps.1114

Williams, V. G., Tremont, G., and Blum, A. S. (2008). Musical hallucinations after left temporal lobectomy. Cogn. Behav. Neurol. 21, 38-40. doi: 10.1097/WNN.0b013e318165a9e1

Wodarz, N., Becker, T., and Deckert, J. (1995). Musical hallucinations associated with post-thyroidectomy hypoparathyroidism and symmetric basal ganglia calcifications. J. Neurol. Neurosurg. Psychiatr. 58, 763-764. doi: 10.1136/jnnp.58.6.763

Wong, C. L., and Bhalerao, S. (2010). Post-surgery musical hallucinations of a patriotic Canadian song. Can. J. Neurol. Sci. 37, 901-903.

Woo, P. Y., Leung, L. N., Cheng, S. T., and Chan, K.-Y. (2014). Monoaural musical hallucinations caused by a thalamocortical auditory radiation infarct: a case report. J. Med. Case Rep. 8:400. doi: 10.1186/1752-1947-8-400

Zungu-Dirwayi, N., Hugo, F., van Heerden, B. B., and Stein, D. J. (1999). Are musical obsessions a temporal lobe phenomenon? J. Neuropsychiatry Clin. Neurosci. 11, 398-400. doi: 10.1176/jnp.11.3.398

Conflict of Interest Statement: The authors declare that the research was conducted in the absence of any commercial or financial relationships that could be construed as a potential conflict of interest.

Copyright (C) 2015 Coebergh, Lauw, Bots, Sommer and Blom. This is an open-access article distributed under the terms of the Creative Commons Attribution License (CC $B Y)$. The use, distribution or reproduction in other forums is permitted, provided the original author(s) or licensor are credited and that the original publication in this journal is cited, in accordance with accepted academic practice. No use, distribution or reproduction is permitted which does not comply with these terms. 